\title{
Author Correction: Neuroimmune disorders of the central nervous system in children in the molecular era
}

Elizabeth Wells, Yael Hacohen, Amy Waldman, Jan M. Tillema, Ariane Soldatos, Beau Ances, Susanne Benseler, Bibi Bielekova, Russel C. Dale, Josep Dalmau, William Gaillard, Mark Gorman, Benjamin Greenberg, Ann Hyslop, Carlos A. Pardo, Robert C. Tasker, E. Ann Yeh, Amit Bar-Or, Sean Pittock, Adeline Vanderver, Brenda Banwell, on behalf of the attendees of the International Neuroimmune Meeting

Nature Reviews Neurology (2018) https://doi.org/10.1038/s41582-018-0024-9

Published online 20 June 2018

In the original version of this Review published online and in print, the contribution of attendees of the International Neuroimmune Meeting to the content of the Review was not acknowledged. The author list has been corrected in the PDF and HTML versions of this article to acknowledge that the Review was written on behalf of attendees of the International Neuroimmune Meeting, and the names of the attendees have been added to the HTML version.

https://doi.org/10.1038/s41582-018-0077-9 I Published online 15 November 2018

\section{Author Correction: Spinocerebellar ataxias: prospects and challenges for therapy development}

Tetsuo Ashizawa, Gülin Öz and Henry L. Paulson

Nature Reviews Neurology (2018) https://doi.org/10.1038/s41582-018-0051-6

Published online 21 August 2018

In Table 3 of this article as originally published, a sentence within the column "Comments" in the row "SCA6" contains an error. The text incorrectly reads "Needs rigorous preclinical studies in SCA3 animal models". This sentence has been corrected to "Needs rigorous preclinical studies in SCA6 animal models" in the PDF and HTML versions of the article.

https://doi.org/10.1038/s41582-018-0102-z I Published online 8 November 2018 